AperTO - Archivio Istituzionale Open Access dell'Università di Torino

\title{
Mental distress: Strategies of sense-making
}

\section{This is the author's manuscript}

Original Citation:

Availability:

This version is available http://hdl.handle.net/2318/75994

since

Published version:

DOI:10.1177/1363459309359719

Terms of use:

Open Access

Anyone can freely access the full text of works made available as "Open Access". Works made available under a Creative Commons license can be used according to the terms and conditions of said license. Use of all other works requires consent of the right holder (author or publisher) if not exempted from copyright protection by the applicable law. 


\title{
health:
}

\section{Mental distress: Strategies of sense-making}

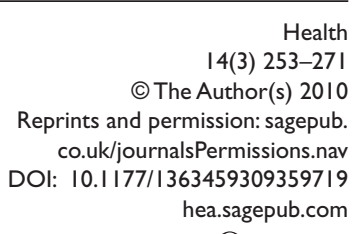

(SAGE

\section{Mario Cardano}

University of Turin, Italy

\begin{abstract}
The irruption of severe mental distress into the life of an individual determines a deep biographical disruption. To cope with this crisis, individuals are involved in a laborious sense-making activity, through the composition of narratives intended to create a new link between past, present and future. This essay analyses the sense-making strategies that follow this dramatic experience through the comparison of four illness narratives composed by Italian participants. The narratives are selected from a broader textual corpus in a way that authorizes their connotation as 'flesh and blood' ideal types. These narratives illustrate three kinds of explanation for the outset of mental distress: the biomedical adopted by Vito; the spiritual-religious adopted by Marta; and the psycho-social adopted by Giacomo.Vito, Marta and Giacomo are still inside the story they are telling, and compose the events by observing them through the eyes of a patient, qualifying their diversity as a stigma. The fourth narrative is different, composed by Serena, a 'voices hearer' who comes to terms with her voices not by silencing them with drugs, but by accepting them as a charisma that has transformed her into a medium and, on final analysis, a balanced woman.
\end{abstract}

\section{Keywords}

mental health, illness narratives, sense-making strategies, voices hearers

\section{Introduction}

The irruption into daily life of a serious pathological condition determines a 'biographical disruption' in the life of an individual (Bury, 1982), which throws him/her into an alien and hostile world. Arthur Frank (1995) describes this passage through a sequence of images of increasing dramatic impact. A serious illness initially emerges as an interruption, the interruption of the progress along a specific biographical trajectory; like the loss of both the map and the destination in a territory which, before the illness, we had planned to

\section{Corresponding author:}

Mario Cardano, Department of Social Sciences, University of Turin, via S. Ottavio, 50, I0I 24 Torino, Italy.

Email: mario.cardano@unito.it 
cross; like a wreckage in which the present dramatically differs from our expectations, revealing an uncertain future (Frank, 1995). All of these traits are amplified in psychic distress - the focus of this article - therefore leaving a condition of wellness introduces a laceration in the biography of the individual which few other forms of distress impose, because here the loss of the map also includes the territories of identity.

Biographical disruption, bewilderment, wreckage, these all portray the experience that accompanies the irruption of the mental distress, delivering an image of a shattered self, weakened, besides the distress, by the need to give a meaning to a new way of being in the world, to answer a set of penetrating questions: 'What has happened to me?', 'Who have I become?' and last but not least, 'Why?' These questions solicit a laborious sense-making activity which leads to the formation of a new narrative, in which a new link between past, present and future is woven, restoring personality also to the narrator, who in this narrative rediscovers his own identity.

This article is dedicated to analysing these narratives, comparing different explanations of the irruption of mental distress and examining the process of selfrebuilding, suspended between the extremes of checkmate and rebirth. The analysis will be conducted by focusing on the narratives of four people, who I will call Vito, Marta, Giacomo and Serena. The four narratives illustrated in the following pages have been collected as part of two research projects, one of which is concluded and the other just started.

The first research study, the source of three of the four interviews I have focused on, was conducted in Turin, between February 2003 and December 2004. ${ }^{1}$ The project was conceived to examine the relationship between work and psychic distress, more specifically to identify factors able to assist psychiatric patients in getting a job. For this purpose, through a sort of case-control design, we compared the narratives, acquired by means of two in-depth interviews, of 50 patients, half of whom were employed, half of whom were unemployed. ${ }^{2}$ The results of the comparison were not particularly surprising: the differences between employed and unemployed were exactly the same as those observed in the general population.

The analysis of their narratives proved to be more interesting, as there were considerable differences in narrative structure and genre, in the relationship instilled between the narrator and the object of value (Gergen, 1994), in this case mental health. Beyond these differences, a trait emerged that united all of the narrators, namely their substantial adhesion to the 'role' of psychiatric patient demonstrated by good pharmacological compliance, combined with a substantially positive approach towards psychiatric institutions. This was associated with a representation of their diversity as a disability; an attitude that can only be understood by bringing together the narratives collected through this project with those from totally different cultural contexts. I refer, in particular, to the 'survivors of mental health system' movements, widespread in English-speaking countries in particular (see Crossley, 2006), or to the Hearing Voices movement (Blackman, 2001; Romme and Escher, 1993), which originated in Holland and has spread especially in the United Kingdom. What these cultural contexts have in common is an attentive critical attitude towards psychiatric institutions combined with a rereading of the patient's diversity not as deviance or stigma, but as a different form of ability, which they can be proud of. 
The second piece of research - still in progress - serves to throw light on this relatively unexplored territory into which I ventured, relying on the collaboration of several key informants belonging to the galaxy of the Italian mental health 'recovery movement'. In this way I came into contact with several groups and associations involved in the mental health sector, and through these a small group of voice-hearers, the 'Gruppo Voci', which is active in a town near Turin. With Gruppo Voci I began a participative research project, aimed above all at bringing out the group's experiences of recent years and collecting some of the more significant testimonials about coping with voices. The first step in this direction was participation in the conference 'Diamo voce alle voci' (Giving Voices a Voice) (Reggio Emilia, 8-9 May 2008), which was conceived and organized to build national co-ordination among self-help groups of voice-hearers. This allowed us to begin our research, which will include 30 in-depth interviews collected using a 'theoretical sampling' strategy. In this essay I will focus on one of the interviews carried out for this study, the interview with Serena, one of the leaders of the Italian Hearing Voices Movement. ${ }^{3}$

The empirical materials produced by the above mentioned studies compose two orders of discourse, the reconstruction of the events (narrative) and the explanation of their concatenation (argumentation). These two orders of discourse were examined using Greimas' (1970) narratological model for analysis of the narratives, and an informal procedure inspired by Toulmin's (1958) analytical model for analysis of the argumentation. ${ }^{4}$ The methodological reading of the two textual corpora produced a body of results which I have decided to illustrate through the analysis of four cases, Vito, Marta, Giacomo and Serena which perform the function of fleshand-blood ideal types: individual people and not just abstract configurations of the attributes which analysis of the empirical documentation characterizes as relevant. The adoption of this case study approach is linked to the decision to illustrate the proposed interpretations with an abundant selection of quotations, thus responding to two specific needs, the first methodological and the second ethical. The first reflects the need for objectivity, to which I have responded by offering the reader an opportunity to compare the proposed interpretations to the widest possible selection of empirical materials that support them. The second need - of an ethical nature - arises from a desire to give a voice to the protagonists of the narratives, in accordance with what Burawoy (2005: 264, 261) defines as the goal of public sociology: that is 'to make the invisible visible', and above all 'making public issues out of private troubles'.

\section{The irruption of mental distress: reconstructions and explanations}

Asked to tell their life stories, Giacomo, Marta, Serena and Vito provided vivid descriptions of the irruption of the mental distress they had experienced, ${ }^{6}$ even though the vantage point from which they compose their own narratives is different. Vito, Marta and Giacomo are, according to Good (1994), still inside the story they are telling, and compose the events by observing them through the eyes of a patient. Serena is a different case, because, as we will see, she tells of her victory over the voices and does so observing them and herself through the eyes of a medium. 
Although the four narratives are comparable in terms of the reconstruction of events, they are not comparable in terms of explanandum: Giacomo, Marta and Vito are seeking explanations for their suffering; Serena speaks of an event, whose nature changes in her story and in her narrative. The voices, the root cause of suffering and deep distress, then become a charisma, a divine gift, on which Serena builds her new identity. This is why I have separated the narratives of Vito, Marta and Giacomo from that of Serena, in the former analysing the explanations of the irruption of mental distress, and in the latter obtaining material that enables a comparison of the various processes of identity reconstruction to be made.

The explanations of the irruption of mental distress formulated by those that are suffering it are the focus of a study conducted by Estroff et al. (1991) on a small sample of psychiatric patients in North Carolina. Four categories of explanations were identified: medical-clinical, emotive-evolutive, socio-situational, religious or spiritual. Medical-clinical explanations qualify psychic suffering as an alteration of the central nervous system; emotional-evolutive ones qualify mental distress as a psychological upset with relation to trauma or more generally aggressions against identity. Identifying specific social circumstances that lead to conditions of poverty or social exclusion as causes of the irruption of the mental distress characterize socio-situational explanations. Finally, religious or spiritual explanations attribute the illness to the intervention of malevolent spirits.

These explanation devices were also applied by the psychiatric patients in Turin, who, together with Giacomo, Marta and Vito formed the sample for the above research project. Half of them account for the outset of their mental distress by referring to only one explanation category, the other half resort to a combination of explanatory arguments, or, better, to an 'exploratory map' (Williams and Healy, 2001), thus shaping a representation of their biographical trajectory 'in the subjunctive mode' (Good, 1994: 153-158), open to numerous interpretations. Furthermore, both in the narratives that lean towards a single category and those which cover more than one, 'pure models', namely those which can be attributed to a specific category beyond doubt, are only rarely encountered. This is demonstrated in particular by explanations which refer both to emotive-evolutive and socio-situational factors. The distinction between these two types of explanation is usually blurry and this led me to group them in a single category: psycho-social explanations. The explanations given by the Turin sample may, therefore, be re-classified into three main categories: prevalently bio-medical, prevalently psycho-medical and prevalently spiritual-religious explanations. The Turin sample, as a whole, is characterized by the prevalence of psycho-social explanations, followed by reconstructions that include both psycho-social and bio-medical factors. Only one case offers a spiritual-magical explanation and that is Marta, who we will be discussing shortly.

The interviews with Vito, Marta and Giacomo provide an ideal-typical illustration of the three cited forms of explanation. Vito's explanation is strictly bio-medical; Marta explains her fate in prevalently spiritual-religious terms; lastly, Giacomo provides an eloquent psycho-social explanation.

\section{Vito: a deplorable sexual intemperance}

Vito considers his condition a 'disease', describing its symptoms and the causes in strictly bio-medical terms. Vito is convinced that the disease he suffers from was triggered by his sexual intemperance during adolescence, particularly by excessive 
masturbation. The link between this behaviour and the irruption of mental distress is defined analytically, by establishing a connection between the biochemistry of the sexual act and brain-cell functioning.

Vito is 31 , and was born in Puglia to a peasant family. Vito had a happy childhood, but during adolescence he experienced the beginning of a crisis in which now he recognizes the roots of his suffering. In the meantime he enrolled in high school, which, despite problems related to studying, he successfully completed. After high school he did his military service and then enrolled at university, where he passed a few exams. It was during those years - close to his 21 st birthday - that Vito was examined by the psychiatric service: the diagnosis, reported in the interview, was 'depression' and a pharmacological treatment was prescribed. However, the treatment did not resolve the 'lack of energy' he had been complaining about for some time. Vito therefore decided to give up studying and look for a job. He left his home region and came to Turin, where he found both a job and the 'right treatment'. Vito lives on his own, but is not lonely: he has a girlfriend, who appears to have restored his faith in his recovery. She has inspired him to realize his dream to achieve a degree in engineering.

The reconstruction of the events that led to the onset of the mental distress is interwoven with their explanation, which becomes more analytical between the first and second interviews. This, which is the key of the two interviews, is shown right from the incipit of the first interview.

It was a very slow, constant, ehm and long thing ... this loss of mental energy. ... Chemical reactions take place in our brains, which release, which give us energy to work, to study to do a .... Depression is a disease where there is a lack of this energy that enables us to work and study and do all of this, all of those things there.

In the beginning, Vito sees his distress as an 'existential crisis' which he links to his problems at school and especially in relations with peers. Vito persuades himself that it is a 'real disease' only much later on, almost by accident, when watching a television programme in which a psychiatrist, with considerable media coverage, is interviewed.

I realized all of this when I heard the interview with professor Cassano on Quark (an Italian television programme of scientific documentary), which talked about this disease here. So I suspected something and I talked to the Mental Health Service ... They gave me the test, Rouch test, Rocharc ... and from that they understood - they told me that ... I was depressed and that's it ... and they gave me some drugs.

On the strength of the diagnosis received and guided by his reaction to the drugs, Vito arrives at his own personal explanation of what happened to him.

So, in my past experience, I had a very intense sex life .... and because I masturbated a lot .... This is my impression, I am not, I repeat, I am not sure, but, I believe that this is the reason, the main cause of my disease. ${ }^{7}$

In the second interview, also assisted by the increased familiarity with the interviewers, Vito provides further detail to his interpretation. 
Because, I think, when you reach orgasm ... our brain secretes pheromons, I think that these hormones are able to inhibit our neurons. They inhibit our neurons in the sense that they lose energy ... and then afterwards our brain recovers a few days later, after which ... after a few days it recovers it, two, three, four days. However, if this happens very frequently ... this here, doesn't let the brain recover and therefore it leads to depression. That's what I think ... it's my own theory, but I think that this is the reason ... I don't know ... lots of doctors say I'm wrong, but in my opinion ...

This conclusion, which Vito tenaciously defends despite the contrary opinions of 'lots of doctors' is corroborated by the observations that he makes of himself, focusing, so to speak, on the amount of energy he needs when, strictly following his prescription of drugs, he has sexual intercourse. It almost seems that Vito sustains how, in psychiatric patients undergoing pharmacological treatment, the link between sexuality and energy impoverishment is more evident:

I think that as we use drugs to produce, to give, to have energy, I think that after sexual intercourse, the fall, the fall in energy, is more accentuated; because the, I mean we consider that this mental energy that is in us, is made in an artificial way.

The explanations developed by Vito, constructed through a critical co-authorship (see Williams, 1984: 181), one moment drawing on themes and lexicon of medical-scientific explanations and the next moment rejecting them, are coherent with the strategies adopted to tackle his own illness. Asked to indicate the 'remedies' that would have enabled him to feel better, Vito, unlike almost all of the other interviewees in the Turin sample, insists on a pharmacological solution: 'to have a stronger drug', able to repair what his 'intemperance' has broken. ${ }^{8}$

\section{Marta: the devil and evil spirits}

The heart of the explanation given by Marta involves the themes of psychic contagion and possession by the devil. Marta is 32, she was born in Turin, where she lives with her parents, who together with Marta are Jehovah's Witnesses. Marta recalls a happy childhood, in which her schoolwork, tackled with enthusiasm - was alternated with sports. Once Marta had finished compulsory school, she enrolled in high school, which she attended with excellent results until the third year, when, just over 17 at the time, she started 'to hear voices', an experience which forced her to abandon school:

I was in the third year of my nursery school teacher's course ... ehm, I had a teacher of Italian who - while in the first and second years [with another teacher] I got good marks - didn't like what I wrote and gave me bad marks, and so I stopped studying. I sat the exam, and I failed ... I didn't study for a bit, then I started to have real problems, the objects around me bothered me while I was studying, and then lots of things ..., I thought and my brain went mad ... I started to hear voices, I was depressed, I thought about suicide.

Just before the end of the school year something happened, which Marta's mother who is present discontinuously in both interviews - recalls as decisive: 
They came one after- afternoon, these two friends, and they said that they had read in $L a$ Stampa [an Italian newspaper] that a girl had been raped in the operating theatre. ... And I, who knows why, I got this idea, that for my wisdom teeth, they put me under general anaesthetic [she is referring to a surgical operation that she had undergone] at night I heard voices, I saw, I saw the scene as if they were raping me. Ehm, nothing, I was convinced, convinced, convinced! My mother said: 'It's not possible!' ... Nothing, I was stuck on the idea, I even went to buy that thing to see if I was pregnant!

This episode, which convinced her mother of the gravity of the crisis her daughter is in, discreetly enters the narrative: partly because Marta had been persuaded that her conviction was nothing but a 'fixation', partly because it is an event that embarrasses her and perhaps - I am guessing - puts her in contact with her own desire, frustrated, of maternity. On this follows another dramatic event which triggered her trajectory of illness: 'because I feel useless ... once I drank some trichloroethylene to kill myself'.

In that period, a long search started to find the appropriate doctor and pharmacological treatment, passing through the search for a name of her suffering, first labelled as 'breakdown' and then as 'schizophrenia'. Marta gives a compound series of explanations for her vicissitudes, among which those that most convince her and that most contribute to shaping her identity involve supernatural causes: demonic possession and that which we can define as psychic contagion. This interpretation is the first to emerge, even though its rapid dissolution in the flow of Marta's arguments makes one think that it is a minor cause, or better, an antecedent to the most important factor, the devil. During a period of hospitalization in psychiatric ward, Marta meets Rosa, another patient and former classmate, with whom she forges a friendship, something she now regrets:

In 92, there, I was with a girl, she was called Rosa, and she was studying to be a nursery school teacher too, she was clever. Then she started, she started not to want to study any more. So her parents ... took her to a magician ... She had visions, she had done some séances with her friends for fun ... I made friends with this girl because she was the only other young patient there! ... we took some photos with this Rosa, photos together in one of those machines that does photos. Then we went to the mountains, to Cogne, where we took some photos together that came out, with the, with that Kodak, that all came out ... ehm, out of focus, with like a really strange thing on these photos. ... [I felt] ill, because they were really horrid things! And since I met her, then I tried to bur ... to burn them I asked her: 'Where are those photos?' I went to visit her with the nurse: 'I haven't got them any more, I haven't got them any more, I've lost them!'

Rosa represents more than one contaminating element: the relationship with a magician, and especially the participation in séances. One could imagine that the photographs of Rosa and Marta together act, in the eyes of the latter, as a device that brings her to share all of those contaminating elements Rosa is afflicted with. ${ }^{9}$ Hence the plan, which unfortunately failed, to sever the bond that mediates the contamination: burning the photos that show her with Rosa.

The second explanation adopted by Marta, in which she specifically blames the devil, is tied to this prior series of events. Marta is on holiday at the seaside with Rosa and the other patients from the Centre for Mental Health and one evening they propose to go to a disco, a form of entertainment condemned by her Church: 
In the disco, I heard voices that told me that if I danced they would enter me and they would teach me to dance. And I started, I started to dance and I felt like a puppet in the hands of someone that was making me move, no? However, I, what did I know, those voices, they all said that those voices were a disease and I thought that [they were] evil spirits. Because we Jehovah's Witnesses believe in the devil, in evil spirits.... And then, and then, at night, I felt like my pelvis was moving on its own, as if I was having sexual intercourse with something invisible, no? Now I don't want to shock you, but I am really sure that it was the devil who ... I risked being expelled [she means from the Congregation of Jehovah's Witnesses]! But as God is love, they understood that I hadn't done any séances on purpose, because you do that on purpose to rebel against God, because you hate him, because, hm, you are bad, because you want to do séances.

The mention of the séances - a practice that Rosa appears to have tried - seems to corroborate the contamination hypothesis illustrated above, which here however disappears to leave room for a new drama, which, with the devil as accomplice, exposes Marta to the risk of being expelled by the people that are most dear to her, her congregation.

Marta therefore sees the devil as the origin not only of her suffering, but of a large part of psychic problems: 'I am convinced that many ... at the origin of mental illness there's the devil.' This is a conviction that Marta tenaciously defends from the objections of her mother and that is tied to the identification of a remedy able to overcome the mental distress, the coming of the Kingdom of God: 'He will dry all tears from their eyes, and there will no longer be death, there will be no more sorrow, nor cries, nor pain, and the previous things are past!'

Alongside this spiritual-religious explanation, Marta's narrative contains a wealth of alternative explanations (see Williams and Healy, 2001), which at times blame the affection denied by her parents, at others, difficulties at school, others still the loss of an important attachment figure, her grandmother, who passed away close to the onset of her first crisis. This compound series of explanations enables Marta to give a sense to her story, without however achieving real reconciliation. Even though supported by her parents and her congregation, Marta appears to be particularly tried by her suffering and by the social consequences it brings: difficulties in finding a job, in creating her own family. Work and love take on the form of a dream that could become reality - says Marta - only when the devil has let her go.

\section{Giacomo: a hostile father and a 'headshrinking' job}

Giacomo brings his psychic suffering into a more familiar territory, with explanations that bring social and psychological factors into play. Giacomo sees the 'pressures' of a 'headshrinking' job as what we may call the proximal cause of his crisis, whose origins, however, can be found in his adolescent years, and his clashes with his father. ${ }^{10}$

Giacomo is 38, and was born in Turin to a working class family who immigrated from the South in the early 1960s. Giacomo talks little of his childhood, limiting himself to recalling an authoritarian father figure. He attended a professional school and obtained a qualification on which to build his career. Giacomo's career - which goes hand in hand with his 'trajectory of illness' (Strauss, 1969) - started in a little workshop, in which he repaired televisions. The experience was positive from all perspectives: the work was pleasant, and he had an excellent relationship with the owner. This ended with the irruption of the mental 
distress, which led Giacomo - at the age of 33 - to leave his job and to go to the Centre of Mental Health. What follows is the story of the difficult conciliation between work and psychic distress; the succession of the pressures of working and those of not working.

In Giacomo's precise and analytical reconstruction of his biographical trajectory, he identifies two crucial moments that coincide with the most severe crises he has experienced. The first crisis took Giacomo by surprise at the age of 33 and was triggered by difficulties encountered in his job, and he tells his story starting with the reconstruction of that event:

I am an electronic technician and following work pressure, that, rushing everything, in a rush, I had a nervous breakdown and I ended up in this Centre. ... I would like to say that I am a very solitary person and therefore I couldn't burden my problems on other people, on friends, like that ...

Giacomo hints at his interpretations of events right at the incipit of his narrative: work and his vulnerability. In the second interview Giacomo describes the first action he took to protect himself from the pressures of work, a short escape to France: 'I said: "that's it, I'm off', so I did a stupid thing ... I went to France and I can't speak a word of French ... for 15 days.' Back from his trip, Giacomo, aware of his unease, decides to go to the Centre for Mental Health: 'for some time I had been thinking that I should go to a psychologist, even when I was feeling better'. Giacomo frequents the Centre for Mental Health for a year and a half. During that period, he is placed in a project regarding the return to work of psychiatric patients, an experience that restores his peace of mind and his self-confidence: 'I was a school cleaner ... I got on really well there, I recharged my batteries ... I found my self-confidence again.' Reinvigorated, Giacomo - close to his 35 th birthday - asks to be rehired at the workshop that he left at the onset of his crisis. Giacomo returns to his old job and the life that he had in the period before the crisis for a year, with an important new factor: he decides to buy a small apartment and live on his own, away from the tension of living with his family. During that period, Giacomo feels well and decides to stop taking his medicine, opening himself up to a second crisis, which arrives soon after, this time fuelled not by the 'pressures' of work but by difficulties experienced in the place he lived:

I had lots of problems with my neighbours ... so much so that I had to stop working again. Because I didn't have any peace of mind, ... I .... I was afraid to go back home in the evenings, I had had some big problems with these people. Because of a door ... which was always left open: they left it continually open ... even in the winter so ... ehm or at night, it was always open. And once I complained to them ... and the next day I found my car ... damaged ... scratched, with the wing mirror broken and everything ... This was when another ... let's say Calvary started because ... precisely, again because of the fact that I was always alone, that I didn't have anyone to talk to, as I was always at home on my own ... and there maybe they shouted, they talked in loud voices, they slammed doors, they hit the walls ... they were arrogant, let's say, my nerves jumped, then ... I had reached a point where I would punch someone, someone walking past me, one of these, that passed in front of me ... and then the police arrived so they called an ambulance, they took me to *** [name of a mental health clinic].

When asked to identify the causes of his distress, Giacomo goes back to his adolescence, to his relationship with his father, to whom he attributes his vulnerability: 
Ehm, I think, I am convinced that my father was a fairly important cause because, as I said, you're living your childhood in constant fear that you can't do anything wrong, not even slightly, ehmh if you get it wrong there's a row, a huge uproar ... So I grew up with a bit of anxiety, with the worry of doing something wrong and of, of ... because it wasn't just if, I don't know, a glass of water spilled on the table, but it was also my ideas. I had my ideas ... my father was against them, but we didn't discuss it: he shouted and imposed his will on me, his point of view and I was someone that didn't understand anything, someone that didn't even know what he was saying, he, he clipped my wings.

In his relationship with his father, Giacomo recognizes the matrix of an undefined 'restlessness', which then became 'unease' when he had to tackle the obstacles that life, and particularly work, threw his way. What Giacomo suffers most from is the pressure of work, and more in general the need to organize his whole existence around the time spent at work, starting from travel time, and through the hassle of having to lunch out. As regards the content of his work, Giacomo is oppressed by a job that forces him into a maze of 'mental conjectures', in which each time he is asked to tackle a problem, on whose solution he is judged, initially by himself, but then also by others; a 'headshrinking' job which worries him: 'I really worried ... the fact of being scared of not being good enough, of not producing enough.'

This strictly psycho-social qualification of the roots of his distress lead Giacomo to identify coherently the most effective remedies. In this perspective, the pharmacological treatment is seen as nothing more than a treatment of the symptoms, from which Giacomo - totally unlike Vito - does not expect a cure, nor the recovery of more equilibrium. The drugs simply serve to drive away the 'bad thoughts', to turn his attention - for a while - away from the reasons for his suffering. The 'treatment' that Giacomo would prescribe for himself is another, not the miraculous drugs of Vito, nor Marta's coming of the Kingdom of God, but something more ordinary: 'a job and some good company'.

This approach, which appears to introduce a spark of hope to a rather dismal narrative, is squashed by Giacomo's more deep-rooted conviction that his life is a failure - no job, no affection and his deep-rooted incurability:

It's not like I am going to change between today and tomorrow, I change and become a more confident person, a calmer, happier person, I am always going to be a bit unhappy, let's say, always a bit like that, with this sadness in me, ehm I don't think that anybody can take this sadness away.

In this scenario, what Giacomo suffers most from is the lacerating conviction of a future in which his chance of life, the possibility of the full exercise of citizenship, are linked to the fine thread of the kindness of others and to charity, sometimes narrow-minded and always difficult to accept:

Instead of leading an independent life I am always, ehm ... let's say bound by ... like that by the goodwill of others, by the kindness of others; I'm not, not mmmh autonomous and independent, I'm dependent on the kindness of others. If others are kind to me, I can get along, if they don't care about me at all, I can't go forward. 


\section{Checkmate and rebirth: forms of self-reconstruction}

The stories of Vito, Marta and Giacomo, although different from many perspectives, converge on a crucial aspect relative to that which Todorov (1978) defines as the epistemological dimension of the narrative, the process through which the narrator gets to know himself, defines his own identity, providing an answer to a fundamental question: 'Who am I?' Giacomo, Marta and Vito reply to this question by defining their image around the figure of a psychiatric patient, qualifying their diversity as a stigma. The latter is particularly evident when compared to another narrative, that of Serena, a 'voices hearer', who has had a similar experience to Marta's, but with a completely different outcome. Serena, like Marta, encounters voices in her life and come to terms with them, not by silencing them with drugs, but by listening to them and accepting them not as a misfortune, but as a precious gift, rewriting her diversity into herself in a more positive way (see Ridge and Ziebland, 2006: 1045).

Serena is 40, born into a well-to-do family in Emilia. The interview portrays a child already in possession of that special gift, which would only later be recognized as such. A few references to that period portray a religious family, a united family that, at the end of the day, demonstrated that they were able to accept Serena, 'the black sheep'. Serena gained a high school diploma in accounting and, soon after, she was hired by an important local firm. Her marriage to Michele took place in more or less the same period. Her husband has always discreetly stood by her, even at the most difficult times, and they only recently separated. We could say that Serena encompasses two lives in one: the first life is the ordinary one, where she is the scrupulous administrative director of a private clinic; in the second, less conventional one, she is a medium who uses her charisma to help those in difficulty. And this is the last stop of a biographical trajectory that started in the late 1980s, when Serena was just under 20 when, following an operation, she went into a coma for a few hours, crossing the threshold that would lead her to the world of the extraordinary:

While I was in the coma, I had an out-of-body experience. That is, I saw my body lying there, I saw what the doctors were doing and I could also hear the voice of my grandmother speaking to me ... Then, once I came around from the coma, I tried to tell my mother what had happened, but she, she said not to talk about it any more ... Then I started to hear voices, and, as my mother didn't want me to talk, I decided not to talk about it to anyone, and for at least two years I didn't talk about it to anyone ...

The voices entered Serena, almost on tiptoe, without the clamour of Marta's experience, leaving everything in its place, from work to the family. Closely following this crisis, Serena approached a religious community, trusting in its support to face her voices. She asked to 'learn how to pray' and for the support of a 'spiritual tutor', but she did not receive attention. She therefore decided to take a different avenue, which in her most recently published book she defines as her own 'research':

My research, at the beginning, was not a spiritual research, but a search for those that were behind that whispering. In the light of day, I didn't see anyone. In the dark of the night I felt 
someone surrounding me, but I didn't understand. At work, I felt like time, my time, was being thrown away. The only place in which I could have found something was unknown to me. So I started to search for that place. You can't see the intangible in the light, and you can't see it in the dark. You can perceive the invisible but you can't touch it. However, I knew that I heard voices and I knew their vibrations well, and I was sure that they were part of a very important invisible dimension, I heard them, but I didn't know them. So I started to look for what I didn't know.

The interview enabled me to clarify with more detail the process described in an almost poetic key in the book from which I took the above excerpt. Serena talks of two years of silence, during which she did not share her experience with anyone, reaching an agreement with the voices: during the day they would let her work in peace, and in exchange she was to dedicate her evenings to them. This was what happened for two years, Serena closed in her room to listen to that 'whispering' and writing everything she heard on the computer. Listening and transcribing the voices - some of which were 'kind', others less so - persuaded Serena of their reality, of the fact that what she heard was not the fruit of her imagination:

I listened and I wrote things I didn't know, that I didn't understand. Then I went to look up the meaning of some of the words I had transcribed in an encyclopaedia - that I didn't know before. In this way I convinced myself that these voices were not just from my imagination, because they told me things I didn't know.

After 'two years of silence', Serena decides to tell her husband, informing him at the same time of her intention to face the voices by consulting them, to get their 'advice, suggestions'. She gets unconditional support from her husband and the listening becomes dialogue:

One day I went to an esoteric bookshop and asked the Voice [a male voice with whom she had a special relationship] to show me a book that would help me ... To which the voice replied: 'Invisible masters'. I went to the shop assistant and I asked him if they had a book under that title, and he said yes, that it was a book by Igor Sibaldi.

Sibaldi's book presented a meditation technique with which it was possible to construct a sort of 'laboratory' in which one could organize one's spiritual experiences. Following the instructions in the book - eyes closed, concentration - Serena continued with her transcription of her evening conversations with the voices, thus increasing her comprehension and control. It was precisely in this 'spiritual laboratory' that Serena heard the voice of her grandfather, who had died several years earlier, who urged her to use her abilities to the benefit of others, 'to help'. Surprised and perhaps a bit incredulous, Serena asked this voice to provide her with proof of his real identity. The grandfather showed her his watch and told her that she could find it in the house he had lived in. The watch was found exactly in the place the grandfather had said: 'in a cupboard, under sheets', and this convinced Serena of the authenticity of that voice, it convinced her that she was 'in contact with someone'. 
The reconstruction of those years continues with an accurate and analytical illustration of the 'proof', at times sought, at others obtained completely involuntarily, of the authenticity of the voices, which had become the sign of Serena's distinctive ability, clairvoyance. Supported by this mass of proof, Serena decides to break the silence with her mother:

I also talked about it to my mother, telling her what had happened to me after the coma, about the voices and these premonitions of mine, these clairvoyant experiences. To which my mother told me that I had also had this thing before the coma, even when I was a child, and she told me that on many occasions, when someone came to visit us, before they went home, I accompanied them to the door and I said 'I bet' I don't know ... 'you will have a little accident', you will do this thing or this other thing. And on many occasions these things happened and they told my mother.... Before, I thought that it had been the coma to provoke these phenomena, however, my mother told me I had always been like that. So I have to think about my story right from the beginning, think that maybe I am really like that and that the coma did nothing but accelerate something that I had inside me.

Serena decides to develop this ability and attends a course in Wales, held by a clairvoyant, where she convinces herself once and for all that 'even the mind has power'. This is how a particular biographical transition started, which slowly transported Serena into the world of mediumism. In the beginning - it was 2000 - she approached a cultural centre in her region which offered parents in mourning for the loss of a son or daughter the opportunity to contact them. She met the founder of the centre, who invited her to put herself to the test as a medium, in contact between parents and their deceased children. Serena was reluctant, afraid of not being able to bear the relationship with individuals that could have been her age; however, the hope of being able to 'help' people in great suffering, as her grandfather had said, encouraged her to put herself to the test:

So perhaps I would be faced with a father of a child of three, 10, 20 years old whatever, or a wife for a husband who had died, and all they had to do was stay in front of me, with or without a photo, and I simply said: 'OK, I can hear the voice of a man, who says this, this and this.' ... I also remained for three, four years in this environment ... however, more than anything, I ehm, I had always had a problem of economic conflict, where, in any event, there were people who were asked for payment ... I felt this conflict a lot, because for me it was an immense gift, I had always considered it a gift, and if, if I had had to give it a value, a price, the price would have been very high to take possession of it, so as I didn't pay anything and it had been given to me, even though it was a trauma in any event, even if I suffered, ehm, I never received any payment for recounting what the voices said, I mean it was worth financial remuneration.

Serena's reflection on what she defines as 'economic conflict' throws light on the outcome of a process of revaluation of her diversity, which is portrayed here as a charisma, a divine gift so great that it imposes generosity, that asks her to put herself at the service of those that are suffering, and to do so absolutely free of charge, because her remuneration is somehow included in the gift. In the same vein of clairvoyance at the service of those in distress, is a commitment that Serena is to take on shortly: listening to the voices of young people in comas on behalf of their relatives who follow their destinies with trepidation. 
With the last of Serena's undertakings, we return to more familiar territory that does not challenge my scepticism. Serena recounts that she was approached by her regional Centre for Mental Health, which, having heard of her very individual experience of tackling the voices, proposed that she should lead a group of voice hearers:

The psychiatrist of *** [name of the place] came forward through a person, an operator, who knew me, ... and said to me: 'Look Serena, psychiatry has this type of problem: there are voice hearers, people that are fine, professionals, lawyers, that come to the department and say: 'I hear voices, I'm not well, give me some tablets because I don't want to hear them any more.' Very balanced people, and the head psychiatrist after three months says: 'This same, balanced person, who has a profession, after hearing voices for three months, went mad' ... 'he gave up on everything, he destroyed his marriage.' And these cases are, eh, increasingly, unfortunately, more common, so in a certain sense there was this huge exchange, they also sought to discover the key that enabled me not to go mad, not to have to be followed by a psychiatrist, not to have taken drugs, what helped me, so he said to me: 'Not that there is an absolute truth' he said 'if your example can be of help to a voice hearer, to say: if you succeeded, I too can succeed ...' ... So I presented this project, I said: 'What is your objective?' [the head psychiatrist] said: 'the best thing would be to form a self-help group' ... I said: 'OK, I will be the facilitator.'

Serena tackles this assignment with the same spirit of service as the more spiritual activities she had performed, aware of how her personal experience, her 'method' of handling the voices can help other hearers:

with each of them I seek to find their equilibrium, but not because Serena has a method, but because with Serena they can talk about it ... and they don't always open up to a psychiatrist because they are given some extra tablets afterwards.

The difference that separates the processes of identity reconstruction documented by Vito and especially by Giacomo and Marta is therefore very evident. Their identity, as we said, is modelled on the role of the psychiatric patient: projected towards a future that envisages recovery for Vito, tied to a desolate present for Giacomo and Marta. The complexity of the biographical trajectories considered, beyond - it goes without saying - the very small number of cases considered, does not permit the development of an explanatory hypothesis. I will therefore confine myself to describing the steps of Serena's construction of another identity, leaving the development of several comparative considerations to the conclusion.

Serena takes the first step towards the reconstruction of her identity by accepting her voices, which in the beginning takes the form of a fearful and on the whole guarded willingness to listen. The acceptance of the voices makes the pact of cohabitation possible, which will enable her to give a meaning to her experience. And this meaning becomes clear at the end of a long reflective journey that allows Serena to recognize the ontological autonomy of that 'whispering', or better, that allows her to separate the 'psychic', 'mental' voices that she attributes to herself, to her own suffering, from the other voices, those behind which there is someone other than herself. In her own 'spiritual laboratory', and above all out of it, Serena gathers proof, confirmation that upholds an interpretation of her experience which gradually takes shape leading her to transform the stigma of psychic suffering into a charisma, a divine gift, that she must share with others. 
So we therefore have Serena well rooted in her new identity, that of a medium who returns her gift by at times helping a mother in mourning, at others a young person in a coma and his or her relatives. From here we have the last step, that which paradoxically leads her to the place that the majority of people with the same experience would have encountered on the first leg of their journey: psychiatry. Here, however, Serena does not have the role of a patient, but of a non-professional expert who shows, through the example of her own life, that there is an alternative, that the 'pill' is not the only possible solution.

The recovery of her agency therefore associates Serena to the communion, to the perception of her own bond with an 'organism', a broader collective subject that she feels a part of and towards whom she makes an investment, expressed above all in the dimension of help, of looking after those in difficulty (McAdams et al., 1996), above and beyond the border that separates the ordinary from the extraordinary.

\section{Conclusions}

The narratives of Giacomo, Marta, Serena and Vito have numerous aspects in common, but also significant differences that mostly regard the characterization of the protagonist and the outcomes of the processes of identity construction interpreted between the lines of their stories. For all of them the experience of psychic suffering provokes a biographical disruption: the destruction of oneself, followed only later by an arduous reassembly of the pieces. Mental distress entails, for all of them, a heavy aggression against their capacity of agency. The consequences of this suffering spread to all areas of their lives: from health, to work, to relationships and love. In the case of Serena, silence 'freezes' the spreading of these effects, which however will materialize later, with the emergence of a new 'extended identity' (Strauss et al., 1975), that of a medium. Lastly, faced with an experience as devastating as mental illness, they are all required to undertake the laborious task of sensemaking, which leads them to account for what had happened and, at the same time, to redraw their profile on the basis of the experience of their particular biographical transition. The most significant differences that I will focus on below emerge as regards this last point, that of self-rebuilding. First, however, we need to return to the journey that led Giacomo, Marta, Serena and Vito to defining their own identity during the course of the narrative provided by the interview.

It is clear, but nonetheless important, how this journey took place within the psychiatric services for Vito, Marta and Giacomo and in other places for Serena. This difference is particularly evident if we compare the stories of Serena and Marta. Surprised by the voices, more or less at the same point in their lives, they learn to live with them with different tools and outcomes. This all contributes to demonstrating with all due precaution - how the consequences of an undoubtedly disturbing event, such as hearing voices, are from many points of view socially constructed, dependent on the characteristics of the context in which they take shape. ${ }^{11}$ What, therefore, can have determined such different outcomes? The foundations upon which I have formulated this question are undoubtedly shaky: either because I am referring to clinical skills I do not possess, or because I am forcing a conclusion on the basis of empirical material that is not fully adequate. However, advancing a few interpretive hypotheses would appear inevitable, for no other reason than to share the responsibility for the exercise, which the comparison of these narratives has no doubt solicited, with the reader. 
A first aspect that comes to our attention is Serena's choice of silence, which protected her experience from the stigma that usually afflicts those who hear voices. This silence opened the interlude in which Serena was able to accept and face the voices, giving them a meaning. In this regard, Marta's attitude was different, as she was never able to accept the voices, perhaps also due to their much more threatening tone. This is linked to a second important aspect, which regards agency. ${ }^{12}$ While on one hand Serena's experience of the voices can be qualified as the outcome of a weakening of her agency, on the other hand, the strategy she adopted of tackling the voices, stipulating a pact, indicate agency and control capacities. Serena's agency contrasts almost mirror-like with Marta's passivity, clearly expressed by her conviction of being possessed by hostile evil spirits that move her body 'like a puppet'. The differences that distinguish the cultural contexts to which Marta and Serena belong do not appear to be any less important. Marta is a Jehovah's Witness, she is part of a cultural context in which the demoniacal voices she hears are possible and unacceptable at the same time (see Good, 1994: 100). This explains how Marta can still say she is convinced of the influence of the devil, and at the same time, can fear the consequences of her conviction. On the basis of that which emerges from the interview, Serena's encounters with the voices take place in a context in which this experience appears less plausible but, at the same time, less hostile. This makes their acceptance easier and, helped by the isolation with which Serena envelops herself, she is able to distinguish between positive voices, to which she should listen, and negative voices with which contact should be minimized. Lastly, consideration should be given to an event that, present only in Marta's narrative, sets off her 'trajectory of illness' within the psychiatric circuit. I am referring to her attempted suicide which alarmed Marta's parents, leading them to take full control of their daughter's life.

Alongside the clear differences between the biographical transitions experienced by Marta and Serena, it is worth considering the less clear-cut ones, which separate the transitions of those that have not yet returned to health. In their autobiographical narratives, Giacomo, Marta and Vito describe three different 'trajectories of illness' (Strauss, 1969), which differ as regards the definition of what triggered them, and the way in which these and other elements are related, creating a specific narrative genre (see Cardano, 2007; Gergen, 1994). Marta and Giacomo's narratives are similar to the genre of tragedy; Vito, in contrast, provides a text that comes close to the genre of a 'comedy romance narrative' (Gergen, 1994: 197); a narrative in which the fall, the slow 'loss of energy' is followed by a recovery that envisages a 'happy ending'. These brief characterizations of the narratives of the three people are linked, and to a certain extent determined, by two other aspects, regarding first of all the qualification of the narrator, and second, the moral dimension that embodies their explanations of the irruption of the mental distress.

Marta and Giacomo characterize their images exclusively around the figure of the psychiatric patient. Vito softens the stigma of this characterization by combining his present-day image with the image of his future self, when a degree in engineering and a more effective drug will return his life to him. The qualification of the agency of the narrator follows the same pattern; once again we have Vito on one side, and Marta and Giacomo on the other. Vito acknowledges - through a TV programme - the signs of his distress as possible depression and seeks help from the mental health centre in his city. Vito's agency capacity arises again soon after when he decides to move far away from home, to try out the world of work after having left his studies. Giacomo, and even more so Marta, demonstrate less ability to control their own lives. 
The moral dimension of the narratives given by Giacomo, Marta and Vito can be seen first of all in their arguments in which they attribute culpability, or at least responsibility, for crossing the border that separates health from illness. Marta, who attributes the responsibility for her suffering to something completely other from herself - the devil - contrasts with Giacomo, who is in a vortex of self-culpability. In this regard, I should clarify how, for Marta, identifying the cause of her suffering as the devil is combined with the acknowledgement of partial personal responsibility, related to her friendship with Rosa, who was the vehicle of contagion. This, together with the threatening nature of the external agent responsible for her suffering, means that Marta cannot feel fully absolved, or pacified. This attitude is shown, on the other hand, by Vito, who builds his explanation on two levels which at first sight appear to be in a state of tension. The first is the qualification of his suffering as an 'organic disease', as a state of affairs in which his will cannot intervene and for which no responsibility can be attributed. Vito's second line of argument moves in the opposite direction, acknowledging his sexual intemperance as the cause of the loss of energy for which he is paying the consequences. The delicacy of the subject did not allow more specific details to be acquired during the interviews; in any event, there is good reason to suppose that Vito's acknowledgement of his own conduct as the cause of his distress is not associated to a profound sense of guilt. Vito, an adolescent at the time, had no knowledge of the consequences of his actions, recognizing such only later, following a clinical diagnosis and his experimentation of the link between drugs and sexuality. This means that the two lines of argument adopted by Vito together mitigate his feelings of guilt, allowing him to look back on his past in a less dismal way, and even more positively towards his future. These observations on the moral dimension of the explanations adopted by Vito, Marta and Giacomo demonstrate an essential quality of illness narratives, their constitutive as well as representative character. Illness narratives, as Kleinman (1988: 49) observes, 'do not merely reflect illness experience, but rather contribute to the experience of the symptoms and suffering'. This emerges with sufficient clarity if we compare the narratives of Serena and Vito, on one side, to those of Giacomo and Marta, on the other. Whereas gift and moral innocence are associated with a less dismal qualification of Serena and Vito's experiences, guilt and fear trigger a decidedly grim portrayal of Giacomo's and Marta's conditions.

As regards the identity reconstruction process, the net contrast between two registers emerges, that of stigma against that of charisma. The narratives of Marta, Giacomo and Vito fall into the first category: with different tones and emphases, all three portray their main character as weighed down by an undesired and undesirable diversity. A stigma Giacomo believes he cannot escape from, and from which Marta and Vito believe they can be fully free only after an extraordinary event: the intervention of Jesus for Marta, and the availability of a miraculous drug for Vito. The idea of charisma, on the other hand, characterizes the narrative of Serena, who has reassembled the fragments of herself, tried by a suffering re-evoked only through a brief mention, accepting and valorizing her diversity as a divine gift that imposes a responsibility to help others.

Beyond the considerable differences that separate the biographical transitions analysed in this article, there is a common trait, defined by Arthur Kleinman (1988: 44-45) as 'quiet heroism', that can be seen in the way in which Giacomo, Marta, Serena and Vito have tackled the obstacles that life has thrown their way, in a combination of grace, spirit and at times even a sense of humour. 


\section{Notes}

1 For a description of the results of this research project, see Cardano (2007).

2 The interviews were carried out by two interviewers, a professional and a non-professional one. The non-professional interviewer was enrolled among the psychiatric patients of the local Unit of Mental Health.

3 All the interviews were tape-recorded and transcribed with the informed consent of each participant.

4 The analysis of the narratives according to the model proposed by Algirdas Julien Greimas is illustrated in Cardano (2007).

5 It should be noted that this means giving a virtual voice, a sort of 'ventriloquism' (see Czarniawska, 2004: 122), since it is the researcher who chooses what parts of the interview transcript will be reproduced and submitted to the reader.

6 The formal diagnoses of Vito, Marta and Giacomo were, respectively, 'schizophrenic psychosis', 'simple schizophrenia' and 'psychosis'. Serena, on the other hand, was never given a psychiatric diagnosis, since she never consulted a psychiatrist to find a name for her so-called 'unusual psychic experiences'.

7 Vito's theory, of a connection between masturbation and mental distress has remote roots. Michel Foucault, in The Abnormals (1999) observed how, between the 18th and 19th centuries a 'crusade' against masturbation was waged in Europe. The manu strupiatione was depicted as a 'possible cause of all possible illnesses'. One of the consequences of this universal pathogenic agent was madness.

8 A similar characterization of the causes of mental illness and the remedies that allow a return to well-being is described in a study by Ridge and Ziebland (2006) on representations of recovery from depression.

9 This association appears to be coherent with the Von Domarus principle, which Arieti considers effective in schizophrenic thought. On the basis of this principle, to establish an identity relationship, for example $\mathrm{A}=\mathrm{B}$, Von Domarus believes that it is sufficient for $\mathrm{A}$ and $\mathrm{B}$ to share one or more predicates (Arieti, 1948: 326-327). On this basis, we can conclude that 'Marta is possessed by evil', moving from these two separate premises: (1) 'Rosa, a person possessed by evil, is shown in this photograph'; (2) 'Marta is shown in this photograph; premises in which the common predicate is being shown in the same photograph.

10 Giacomo's narration combines a variety of explanatory arguments that correspond to a surprising degree with those observed by Williams and Healy (2001) among new referrals to a community mental health team. Giacomo refers a 'pressurized lifestyle', linking its impact to the vulnerability of his personality, which he attributes in turn to an early conflictual relationship with his father. Once again we see a plurality of explanatory arguments, or an 'exploratory map' (Williams and Healy, 2001); arguments that - placed side by side - support that 'subjunctivation of reality' described by Good (1994: 153-158).

11 This observation sustains the position of Romme and Escher (1993: ch. 11) for whom 'the real problem is not so much hearing the voices per se, as the inability to face this experience'.

12 For a discussion of the importance of agency in composition of a narrative of self that is able to promote the recovery process, see Ridge and Ziebland (2006: 1052). 


\section{References}

Arieti S (1948) Special Logic of Schizophrenic and Other Types of Autistic Thought. Psychiatry 11: $325-338$.

Blackman L (2001) Hearing Voices: Contesting the Voice of Reason. London: Free Association Books. Burawoy M (2005) 2004 American Sociological Association Presidential Address: For Public Sociology. British Journal of Sociology 56(2): 259-294.

Bury M (1982) Chronic Illness as Biographical Disruption. Sociology of Health and Illness 2(2): $167-182$.

Cardano M (2007) 2007 'E poi cominciai a sentire le voci...': Narrazioni del male mentale. Rassegna Italiana di Sociologia XLVIII(1): 9-56.

Crossley N (2006) Contesting Psychiatry: Social Movements in Mental Health. London: Routledge. Czarniawska B (2004) Narratives in Social Science Research. London: SAGE.

Estroff SE, Lachicotte WS, Illingworth LC, and Johnston A (1991) Everybody's Got a Little Mental Illness: Accounts of Illness and Self among People with Severe, Persistent Mental Illnesses. Medical Anthropology Quarterly 5(4): 331-369.

Foucault M (1999) Les anormaux: Cours au Collège de France, 1974-1975. Paris: Gallimard. Frank A (1995) The Wounded Storyteller: Body, Illness and Ethics. Chicago, IL: University of Chicago Press.

Gergen KJ (1994) Realities and Relationship. Cambridge, MA: Harvard University Press.

Good B (1994) Medicine, Rationality, and Experience: An Anthropological Perspective. Cambridge: Cambridge University Press.

Greimas AJ (1970) Du sens. Paris: Éditions du Seuil.

Kleinman A (1988) The Illness Narratives: Suffering, Healing and the Human Condition. New York: Basic Books.

McAdams DP, Hoffman BJ, Mansfield ED, and Day R (1996) Themes of Agency and Communion in Significant Autobiographical Scenes. Journal of Personality 64(2): 339-377.

Ridge D, Ziebland S (2006) 'The Old Me Could Never Have Done That': How People Give Meaning to Recovery Following Depression. Qualitative Health Research 16(8): 1038-1053. Romme M, Escher S (eds) (1993) Accepting Voices. London: Mind. Strauss A (1969) Mirrors and Masks. Mill Valley, CA: The Sociology Press.

Strauss A, Corbin J, Fagerhaugh S et al. (1975) Chronic Illness and the Quality of Life. SaintLouis, MO: Mosby Co.

Todorov T (1978) Les genres du discours. Paris: Éditions du Seuil.

Toulmin S (1958) The Uses of Argument. Cambridge: Cambridge University Press.

Williams B, Healy D (2001) Perceptions of Illness Causation among New Referrals to a Community Mental Health Team: 'Explanatory Model' or 'Exploratory Map'? Social Science \& Medicine 53(4): 465-476.

Williams G (1984) The Genesis of Chronic Illness: Narrative Re-Construction. Sociology of Health and Illness 6(2): 175-200.

\section{Author biography}

Mario Cardano (PhD) is Professor of Qualitative methods for social research at the University of Turin (Italy). His current research interests focus on mental health and on the experience of dyslexia. 